\title{
CYFRA 21-1 as a tumour marker for bronchogenic carcinoma
}

\author{
M. Rapellino*, J. Niklinski+, F. Pecchios, M. Furman+, S. Baldi*, \\ L. Chyczewski++, E. Ruffini**, E. Chyczewska ${ }^{\$ \$}$.
}

CYFRA 21-1 as a tumour marker for bronchogenic carcinoma. M. Rapellino, J. Niklinski, F. Pecchio, M. Furman, S. Baldi, L. Chyczewski, E. Ruffini, E. Chyczewska. @ERS Journals Ltd 1995.

ABSTRACT: Despite extensive research, the role of the commonly employed tumour markers in the diagnosis of lung carcinoma is yet to be clarified. The utility of a new marker, CYFRA 21-1, in the preoperative evaluation of patients with bronchogenic carcinoma was investigated.

CYFRA 21-1 was determined with a radiometric assay in serum of 280 patients with lung cancer and 208 patients with various nonmalignant lung diseases.

The levels of the marker were significantly higher in lung cancer patients. Among benign lung diseases, elevated CYFRA 21-1 levels were found in pulmonary fibrosis. Using a cut-off of $3.2 \mathrm{ng} \cdot \mathrm{ml}^{-1}$ (95th percentile of levels obtained in benign lung disease), the total sensitivity of the marker was $48 \%$. The best sensitivity was obtained in squamous cell lung cancer $(60 \%)$. The highest values of CYFRA 21-1 were found in metastatic lung cancer, and the marker sensitivity was more elevated in stage IIIb and IV. On the other hand, $40 \%$ of patients with surgically resectable lung cancer had CYFRA 21-1 levels above the cut-off.

We conclude that CYFRA 21-1 may be satisfactorily employed in the differential diagnosis between malignant and benign lung diseases in association with other clinical and radiological data.

Eur Respir J., 1995, 8, 407-410.

\author{
*Dept of Pneumology, Molinette Hospital, \\ Torino, Italy. **Dept of Thoracic Surgery, \\ University of Torino, Torino, Italy. ${ }^{\$}$ Clini- \\ cal Chemistry, Susa-Avigliana Hospital, \\ Avigliana, Torino, Italy. Depts of ${ }^{+}$Thoracic \\ Surgery, ${ }^{++}$Pathology, \$\$Pneumology, \\ Medical School, Bialystok, Poland. \\ Correspondence: M. Rapellino, \\ Servizio di Fisiopatologia Respiratoria \\ Ospedale Molinette \\ Via Genova 3 \\ 10126, Torino \\ ltaly
}

Keywords: Cytokeratins

lung cancer

tumour markers

Received: July 121994

Accepted after revision December 231994
Several circulating tumour markers for bronchogenic carcinoma have been identified. Despite extensive research, however, their role in the diagnosis of the disease remains unclear. Nonetheless, the clinical use of carcinoembryonic antigen (CEA) [1, 2], neuron-specific enolase (NSE) [3-5], tissue polypeptide antigen (TPA) [6-8] and squamous cell carcinoma (SCC) antigen $[9,10]$ in the diagnosis and follow-up of patients with bronchogenic carcinoma is widespread.

Recent studies have focused on a new family of markers resulting from some cellular degradation products. These molecules, which include cytokeratins and other intermediate filaments of the cell, like vimentin and desmin, have gained popularity after the development of monoclonal antibodies (MoAbs), which allow a histopathological differentiation and classification of physiological and pathological tissues. Moll et al. [11] and BROERs et al. [12] employed a panel of MoAbs against subtypes of cytokeratins to demonstrate the distribution pattern of cytokeratins in the different histological types of bronchogenic carcinoma. The subtype 19 was the most frequent in the cytoplasm of the tumour cells.

The next step was the observation that, unlike the original cytokeratins, fragments of intermediate filaments are soluble in serum, and can, therefore, be detected and measured with the aid of MoAbs. As a consequence, a fragment of cytokeratin subunit 19, the CYFRA 21-1, can be measured by a immunometric assay using the two mouse MoAbs KS 19-1 and BM 19-21. According to preliminary investigations, CYFRA 21-1 shows a good specificity-sensitivity profile in bronchogenic carcinoma, especially in the squamous cell type. The purpose of this investigation was: 1) to define more precisely the correlation between serum CYFRA 21-1 levels and various nonmalignant lung diseases; and 2) to assess pretreatment marker levels in relation to histological type and extent of lung cancer.

\section{Material and methods}

We determined CYFRA 21-1 with immunoradiometric assay (CIS Italy, CIS BIO International) on serum in 280 consecutive patients observed in two Thoracic Surgical Units (251 males and 29 females) with a cytological or histological diagnosis of lung cancer (LC), and in 208 patients (178 males and 30 females) with benign lung disease (BLD). Among patients with LC, 158 had squamous cell carcinoma (SCC), 85 had adenocarcinoma of the lung (ACL), 23 undifferentiated large-cell lung carcinoma (LCLC) and 14 small-cell lung carcinoma (SCLC). The histopathological and cytological material was examined by two pathologists of the same service, independently. Routine pretreatment staging 
Table 1. - CYFRA 21-1 levels $\left(\mathrm{ng} \cdot \mathrm{ml}^{-1}\right)$ in benign lung disease

\begin{tabular}{|c|c|c|c|c|c|c|}
\hline & \multirow[t]{2}{*}{ Mean } & \multirow[t]{2}{*}{$\mathrm{SD}$} & \multirow{2}{*}{ Median } & \multirow[t]{2}{*}{ Range } & \multicolumn{2}{|c|}{$>3.2 \mathrm{ng} \cdot \mathrm{ml}^{-1}$} \\
\hline & & & & & $\mathrm{n}$ & $\%$ \\
\hline COPD & 1.6 & 0.8 & 1.4 & $0.4-4.4$ & $4 / 63$ & 6 \\
\hline Pulmonary fibrosis & $1.8^{*}$ & 1.1 & 1.3 & $0.5-4.1$ & $6 / 32$ & $19 * * *$ \\
\hline Sarcoidosis & 1.2 & 0.5 & 1.0 & $0.3-2.6$ & $0 / 38$ & \\
\hline Benign tumours & $2.2 * *$ & 0.7 & 2.2 & $0.8-3.9$ & $1 / 16$ & 6 \\
\hline Tuberculosis & 1.5 & 0.7 & 1.4 & $0.3-3.0$ & $0 / 23$ & \\
\hline Pneumonia & 1.2 & 0.4 & 1.0 & $0.4-2.1$ & $0 / 18$ & \\
\hline Asthma & 1.1 & 0.9 & 1.0 & $0.2-4.0$ & $1 / 18$ & 6 \\
\hline All BLD & 1.5 & 0.8 & 1.3 & $0.2-4.4$ & $12 / 208$ & 6 \\
\hline
\end{tabular}

COPD: chronic obstructive pulmonary disease; BLD: benign lung disease; CYFRA 21-1: cytokeratin 19 fragment; SNK StudentNeuman-Keuls. *: $\mathrm{p}<0.05$ vs sarcoidosis, asthma (SNK rest); ${ }^{*}: \mathrm{p}<0.05$ vs sarcoidosis, tuberculosis, pneumonia, asthma (SNK test); ***: $\mathrm{p}=0.05$ (Chi-squared test).

procedures included physical examination, blood chemistry profile, chest radiography, bronchoscopy, computed tomography of the chest and brain, and ultrasonography of the liver. In addition, bone scan and bone marrow biopsy were performed in the evaluation of SCLC patients, and where necessary. Selected patients underwent mediastinoscopy. All patients with malignancy were classified according to TNM (primary tumour, regional lymph node involvement, occurrence of distant metastasis) classification [13]. Sixty patients were stage 1, 49 stage II, 87 stage IIIa, 23 stage IIIb, and 61 stage IV.

The diagnosis of BLD was usually based on clinical, biochemical, bacteriological and radiological findings. In some cases (benign lung tumours, pulmonary fibrosis and tuberculoma of the lung), the diagnosis was made by surgery. To determine CYFRA 21-1 serum levels, venous blood samples were collected from each patient before therapy. Serum samples were obtained by centrifugation and stored at $-70^{\circ} \mathrm{C}$ until assayed. The cutoff point was at $3.2 \mathrm{ng} \cdot \mathrm{ml}^{-1}$ (95th percentile of marker levels obtained in patients with BLD). False positives were defined as BLD patients with tumour marker levels above $3.2 \mathrm{ng} \cdot \mathrm{ml}^{-1}$.

A preliminary statistical analysis (Shapiro-Wilk test) revealed that the distribution of CYFRA 21-1 levels follows a normal distribution. Consequently, we adopted one-way analysis of variance, correcting the significance level for multiple comparisons, with Student-NeumanKeuls (SNK) test. Chi-squared test was also used, as appropriate. Statistical significance level was 5\%

\section{Results}

Table 1 shows mean, standard deviation, median and range of CYFRA 21-1 levels obtained in BLD patients. The number of false positive cases and percentages are also indicated. The marker levels in patients with pulmonary fibrosis and benign lung tumours were significantly higher than in other BLD groups. In addition, the number of false positive cases was significantly increased in patient with lung fibrosis.

Table 2 demonstrates the behaviour of CYFRA 21-1 in patients wilh LC, according to histological types. Marker levels obtained in LC patients were significantly higher than those of BLD subjects. There was a significant difference among the histological types $(\mathrm{p}<0.002)$ (one-way), but SNK test was not significant in single comparisons. The highest sensitivity was found in SCC, whilst only two out of 14 SCLC patients had CYFRA 21-1 levels above the cut-off.

Table 3 illustrates the CYFRA 21-1 serum levels as related to stage of disease. The levels found in stage IV were significantly higher than in every other stage. The sensitivity of CYFRA 21-1 was more elevated in advanced disease, but the level of significance was not reached.

Table 2. - CYFRA 21-1 levels $\left(\mathrm{ng} \cdot \mathrm{ml}^{-1}\right)$ in lung cancer according to histological type

\begin{tabular}{lcccccc}
\hline & Mean & SD & Median & Range & \multicolumn{2}{c}{$>3.2 \mathrm{ng} \cdot \mathrm{ml}^{-1}$} \\
& & & & & $\mathrm{n}$ & \multicolumn{2}{c}{$\%$} \\
\hline SCC* & 8.8 & 13.2 & 5.0 & $0.9-89$ & $95 / 158$ & $60^{* * * *}$ \\
ACL & 4.1 & 4.8 & 2.8 & $0.6-35.7$ & $32 / 85$ & 38 \\
LCLC & 4.0 & 3.5 & 2.7 & $1-14.9$ & $7 / 23$ & 30 \\
SCLC & 2.8 & 3.1 & 2.0 & $1-12.9$ & $2 / 14$ & 14 \\
\hline All LC** & 6.7 & 10.6 & 3.1 & $0.6-89$ & $136 / 280$ & 49 \\
\hline
\end{tabular}

SCC: squamous cell carcinoma; ACL: adenocarcinoma of the lung; LCLC: large-cell lung carcinoma; SCLC: small cell lung carcinoma; LC: lung carcinoma. For further abbreviations see legend to table 1. *: one-way analysis of variance among four histological types, $\mathrm{p}=0.002$; **: $\mathrm{p}=0.001$ vs BLD levels (one-way analysis of variance); ***: $\mathrm{p}=0.05$ (Chi-squared test). 
Table 3. - CYFRA 21-1 levels (ng. $\left.\mathrm{ml}^{-1}\right)$ in lung cancer according to TNM stage

\begin{tabular}{|c|c|c|c|c|c|c|}
\hline \multirow{2}{*}{$\begin{array}{l}\text { TNM } \\
\text { Stage }\end{array}$} & \multirow[t]{2}{*}{ Mean } & \multirow[t]{2}{*}{ SD } & \multirow[t]{2}{*}{ Median } & \multirow[t]{2}{*}{ Range } & \multicolumn{2}{|c|}{$>3.2 \mathrm{ng} \cdot \mathrm{ml}^{-1}$} \\
\hline & & & & & $\mathrm{n}$ & $\%$ \\
\hline I & 3.0 & 2.3 & 2.4 & $0.6-12.6$ & $17 / 60$ & $28^{\dagger}$ \\
\hline II* & 4.5 & 3.3 & 3.3 & $1-16.6$ & $25 / 49$ & 51 \\
\hline IIIa* & 5.1 & 5.5 & 3.0 & $1-35.7$ & $37 / 87$ & 43 \\
\hline III'b* & 7.6 & 6.8 & 5.2 & $1-28.9$ & $16 / 23$ & 70 \\
\hline $\mathrm{IV} * \$$ & 13.8 & 19.4 & 5.2 & $1-89$ & $41 / 61$ & 67 \\
\hline
\end{tabular}

TNM: primary tumour, regional lymph node involvement, occurrence of distant metastases. For further abbreviations see legend to table 1. *: p<0.05 vs BLD (SNK test); : $_{\text {: }}<0.05$ vs I, II, IIIa, IIIb (SNK test); †: Chi-squared Ns, not significant.

\section{Discussion}

Recently, a new tumour marker, CYFRA 21-1, was described for the determination of cytokeratin 19-fragment in serum. The results on CYFRA 21-1 were first published in 1992 and showed its value in lung cancer patients [14]. Despite these interesting results, however, CEA still remains the gold standard of tumour markers for non-small-cell lung cancer, although the results so far obtained are not encouraging.

In this study, we investigated the levels of CYFRA 21-1 in patients with different nonmalignant lung diseases, including benign tumours. In benign lung diseases, serum CYFRA 21-1 levels were rarely elevated. However, marker levels were more frequently increased in patients with pulmonary fibrosis [19\%]. Other markers, including CEA and TPA, show a similar behaviour. In a previous study [15], we found elevated serum levels of these markers in pulmonary fibrosis and chronic obstructive pulmonary disease (COPD), whilst no false positives were observed in sarcoidosis. This could be due to the extensive hyperplasia of the bronchioloalveolar epithelium, rich in keratins, typical of pulmonary interstitial fibrosis. Conversely, low marker levels can be found in sarcoidosis, mainly in stage I disease, in which the lung injury is usually limited.

We further observed, in a different study [16], that a percentage of cases of interstitial fibrosis shows a CEA-like immunoreactivity, confined to bronchiolar cells and type II pneumocytes. The influence of other extrapulmonary benign diseases on circulating CYFRA 21-1 levels has also been investigated [17]. Benign urological and gastrointestinal diseases possess only slight influence on this marker, whereas a definite increase of CYFRA 21-1 levels was observed in patients with renal failure.

There are also other notes of interest in this study. As other authors have reported [18, 19], there was a significant link between histological tumour type and CYFRA 21-1 levels. High CYFRA 21-1 serum levels occur more frequently in squamous cell type $(60 \%)$. In the remaining lung carcinoma types, the sensitivity of the marker was significantly lower.

In contrast to our present study and other reports [1821], STIEBER et al. [17], found that increased CYFRA 211 levels were seen in $79 \%$ of patients with squamous cell carcinoma, $54 \%$ of patients with adenocarcinoma,
$65 \%$ with large-cell carcinoma and $52 \%$ with small-cell type, with an overall sensitivity of $61 \%$.

For lung cancer cases the sensitivity was also calculated according to tumour stages. An increased sensitivity was found in advanced stages, with a statistically significant difference between stages I-IIIb and IV. Interestingly, the marker levels obtained in BLD were significantly different from those found in stages II, IIIa, IIIb and IV of bronchogenic carcinoma. A clear correlation between CYFRA 21-1 levels and both stage and tumour size was observed by others [20, 22], suggesting that serum CYFRA 21-1 levels may reflect the tumour mass.

On the other hand, the sensitivity of CYFRA 21-1 in stages I-IIIa, (still surgically resectable), was 40\% (79 out of 196). Among these 79 cases, 23 (29\%) had negative sputum cytology as well as negative cytological and/or histological specimens obtained at bronchoscopy. Fourteen of the 23 patients underwent fine needle transthoracic biopsy, which was positive in 11 . Hence, in 12 out of 79 patients $(15 \%)$ the diagnosis of malignancy was not cytologically or histologically confirmed before surgery. In these cases, elevated CYFRA 21-1 level was the only positive finding.

In summary, CYFRA 21-1 is a valuable tumour marker for bronchogenic carcinoma, with a good sensitivity and specificity, particularly in the squamous cell type. CYFRA 21-1 determination may be satisfactorily employed in the differential diagnosis between malignant and benign lung diseases in association with other clinical and radiological findings. The acceptable sensitivity in the relatively early stages of bronchogenic carcinoma appears the most interesting result of our study. In addition, our experience indicates that there are differences of marker levels in different benign lung diseases.

We conclude that marker levels in benign lung diseases should be reported separately for various disease entities. This is essential in order to obtain optimal information on the specificity of the markers, avoiding the useless, conflicting results, that have sometimes been published in the literature.

\section{References}

1. Vincent RG, Chu TM, Fergen TB, Ostrander M. Carcinoembryonic antigen in 228 patients with carcinoma of the lung. Cancer 1975; 36: 2069-2076. 
2. Dent PB, McCulloch PB, Wesley-James O, MacLaren R, Muirhead W, Dunnet CV. Measurement of carcinoembryonic antigen in patients with bronchogenic carcinoma. Cancer 1978; 42: 1484-1491.

3. Cooper EH, Splinter TAW, Brown DA, Muers MF, Peake $\mathrm{MD}$, Pearso SC. Evaluation of a radioimmunoassay for neuron-specific enolase in small cell lung cancer. Br J Cancer 1985; 52: 333-338.

4. Weynants P, Humblet Y, Canon JL, Symann M. Biology of small-cell lung cancer: an overview. Eur Respir $J$ 1990; 4: 699-714.

5. Rapellino M, Pecchio F, Ruffini E, Cellerino A. Pathophysiology and clinics of neuron-specific enolase (NSE). In: Ballesta AM, Torre GC, Bombardieri E, Gion M, Molina M, eds. Up-dating on Tumor Markers in Tissue and in Biological Fluids. Torino, Minerva Medica Ed, 1993; pp. 283-297.

6. Buccheri GF, Ferrigno D, Sartoris AM, Violante B, Viola F, Curcio A. Tumor markers in bronchogenic carcinoma. Cancer 1987; 60: 42-50.

7. Buccheri GF, Ferrigno D. Prognostic value of tissue polypeptide antigen in lung cancer. Chest 1992; 101: 1287-1292.

8. De Angelis G, Bigioni D, Leonatti C, Pigorini F. Serum carcinoembryonic antigen (CEA), tissue polypeptide antigen (TPA) and neuron-specific antigen (NSE) for monitoring lung cancer and correlation with metastases. J Tumor Marker Oncol 1988; 3: 15-20.

9. Pecchio F, Rapellino M, Ricci E, et al. TA 4-SCC versus CEA sensitivity for lung cancer. Tumori 1988; 74 : 393-395.

10. Mino N, llio A, Hamamoto K. Availability of tumorantigen 4 as a marker of squamous cell carcinoma of the lung and other organs. Cancer 1988; 62: 730-734.

11. Moll R, Franke WW, Schiller DL, Geiber B, Krepler R. The catalog of human cytokeratins: patterns of expression in normal epithelia, tumors and cultured cells. Cell 1982; 31: 11-24.

12. Broers JLV, Ramaekers FCS, Rot MK, et al. Cytokeratins in different types of human lung cancer as monitored by chain- specific monoclonal antibodies. Cancer Res 1988; 48: 3221-3229.

13. Mountain CF. New international staging system for lung cancer. Chest 1986; 89 (Suppl. 4): 225-233.

14. Bodenmuller H, Banauch D, Ofenloch-Hanle B, Jaworek D, Dessauer A. Technical and clinical evaluation of a new assay for NSCLC, the Enzymun Test CYFRA 21-1. Proc AACR 1992; 33: 203.

15. Rapellino M, Pecchio F, Libertucci D, et al. Serum CEA and TPA levels in various benign lung diseases. Anticancer Res 1992; 12,6A: 1825.

16. Abbona GC, Papotti M, Gugliotta P, Pecchio F, Rapellino M. Immunohistochemical detection of carcinoembryonic antigen (CEA) in nonneoplastic lung disease. Int $J$ Biol Markers 1993; 8: 240-243.

17. Stieber P, Dienemann H, Hasholzner U, et al. Comparison of cytokeratin fragment 19 (CYFRA 21-1), tissue polypeptide antigen (TPA) and tissue polypeptide specific antigen (TPS) as tumour markers in lung cancer. Eur $J$ Clin Chem Clin Biochem 1993; 31: 689-694.

18. Tuchais C, Daver A, Tuchais E, et al. Preliminary clinical evaluation of cytokeratin 19 fragment seric measurement by CYFRA 21-1 assay. In: Galteau MM, Siest G, Henny J, eds. Biologic Prospective. Comptes Rendus du 8 Colloque de Pont-a-Mousson. Paris, John Libbey Eurotext, 1993; pp. 655-658.

19. Niklinski J, Furman M, Chyczewska E, et al. Evaluation of CYFRA 21-1 as a new marker for non-small-cell lung cancer. Eur J Cancer Prev 1994; 3: 227-230.

20. Pujol JL, Grenier J, Daurès JP, Daver A, Pujol H, Michel FB. Serum fragment of cytokeratin subunit 19 measured by CYFRA 21- 1 immunoradiometric assay as a marker of lung cancer. Cancer Res 1993; 53: 61-66.

21. Devine PL, Yarker JY, Fong KM, et al. Serum marker CASA, CEA, CYFRA 21-1, MSA, NSE, TPA and TPS in lung cancer. Int J Oncol 1994; 4: 1129-1135.

22. Ebert W, Leichtweis B, Schapohler B, Muley Th. The new tumor marker CYFRA 21-1 is superior to SCC antigen and CEA in the primary diagnosis of lung cancer. Tumordiagn Ther 1993; 14: 91-99. 